\title{
Studies on epoxy-polysulfone blend ${ }^{\dagger}$
}

\author{
D RATNA, M PATRI, B C CHAKRABORTY, C MADHAVAN and \\ P C DEB \\ Naval Materials Research Laboratory, Naval Dockyard, Bombay 400 023, India
}

\begin{abstract}
Synthesis of carboxyl terminated poly (ethylene glycol adipate) (CTPA) and amine terminated poly(amide sulfone) (PS) based on the CTPA and an aromatic diamine has been described. The products were characterized by ${ }^{13} \mathrm{C}$ NMR and IR spectroscopic analysis, nonaqueous titration, viscosity measurement and solubility characteristic studies. Effect of incorporation of the developed PS on epoxy matrix was studied. Epoxy-PS blends were evaluated with respect to their thermal and dynamic mechanical properties.
\end{abstract}

Keywords. Synthesis; poly(ethylene glycol adipate); poly(amide sulfone); dynamic-mechanical properties.

\section{Introduction}

Epoxy resins are a class of versatile polymer material which form network on curing and are used extensively as matrix for fibre reinforced plastics (FRP), surface coating and structural adhesive. This is because of their high strength, low creep, very low cure shrinkage, good performance at elevated temperature, excellent resistance to corrosion and good adhesion to many substrates. However, unmodified epoxies are relatively brittle with poor resistance to crack growth. Hence modification of epoxy resin has been the subject of intense research throughout the world. Use of flexible long chain hardeners and reactive diluents have been reported in the literature (Peters and Logan 1975). Since it was shown by McGarry and Willner (1968) that carboxyl terminated copolymer of butadiene and acrylonitrile (CTBN) is useful for the fracture toughness of epoxy resins, much work has been done in this field (Reiw 1981; Bascom and Hunston 1989). Other reactive liquid rubbers have also been examined e.g. amine ended butadiene acrylonitrile oligomer (Riffle et al 1982), carboxyl ended polyisobutylene (Slysh 1970), functionalized siloxane and acrylates (Riffle et al 1982; Banthia et al 1989). Modification of epoxy resins with various types of ductile thermoplastics has been studied as alternative to reactive rubbers for improving toughness of epoxy resin. Among thermoplastics poly (etherimide)s (Bucknall and Gilbert 1989; Bauer et al 1989), poly(aryl ether ketone)s (Jang et al 1989; Ijima et al 1991), poly(phenylene oxide) (Yee and Pearson 1990), functionalized polysulfones (Pak et al 1993) have been reported as effective modifiers.

The aim of the present work is to develop a low molecular weight liquid poly (ether amide sulfone) (PS) starting from indigenous precursor and to examine its effect as an impact modifier for epoxy. The synthesis and characterization of PS, study of its compatibility with epoxy and thermal properties are discussed in the present paper. Evaluation of the modified epoxy as a structural adhesive and matrix for fibre reinforced composite with respect to its mechanical properties, impact resistance and adhesive properties will be presented in a later communication.

\footnotetext{
'Paper presented at the poster session of MRSI AGM VI, Kharagpur, 1995
} 


\section{Experimental}

\subsection{Materials}

Poly(ethylene glycol) (PEG 400 and PEG 1000), Glaxo Laboratories, Bombay (India); adipic acid, S.D Fine Chem. Bombay (India); 4,4' diamino diphenyl sulfone (DDS), Suvidhinath Laboratories, Baroda (India); para toluene sulfonic acid (PTSA), Sisco Laboratories, Bombay (India) were used as received.

The epoxy resin was a liquid diglycidyl ether of bisphenol A type (Ciba Geigy, Araldite LY 556) with an equivalent weight per epoxide group of $195 \pm 5$. Ambient temperature hardener (Ciba Geigy, HY 951) was used as curing agent. The solvents toluene, methanol etc, were of analytical grade (BDH, India).

\subsection{Synthesis of polysulfone}

Polysulfone was synthesized by a two-step reaction. First step was the preparation of carboxyl terminated PEG adipate (CTPA) by reacting PEG with adipic acid in $1: 1.5$ ratio with $0.5 \%$ by weight of para toluene sulfonic acid as catalyst. The reactions were carried out in three necked reaction flask fitted with a stirrer, nitrogen inlet and Dean and Stark condenser. The water formed during reaction was removed continuously from the reaction mixture using toluene as azeotropic solvent. The reaction was monitored from the amount of water collected. After the completion of reaction (reaction time was about $4 \mathrm{~h}$ ), the reaction mixture was subjected to vacuum distillation at $70-80^{\circ} \mathrm{C}$ until the product weight remained constant. PEG adipate thus obtained was further reacted with DDS at $165^{\circ} \mathrm{C}$. The reaction was continued until the acid value reduced to a minimum value (about 20 ). The time taken was about $14-16 \mathrm{~h}$. The final product PS was then characterized.

\subsection{Characterization}

Carboxyl contents were determined by titration with $0.10(\mathrm{~N}) \mathrm{KOH}$ solution in methanol using phenolpthaline as indicator.

Viscosity measurements were carried out by Haake Rotoviscometer $(\mathrm{RV}-3)$ at a shear rate range of $0-100 \mathrm{~s}^{-1}$.

${ }^{13} \mathrm{C}$ NMR spectra were recorded on $500 \mathrm{MHz}$ FTNMR instrument (Brucher AMX-500) using dimethyl sulfoxide as solvent and tetramethylsilane as internal standard.

IR spectra were taken in FTIR spectrophotometer (Perkin Elmer Model 1650).

Solubility parameters were determined by the method described in the literature (Hansen 1967).

Chemical coupling of PS with epoxy was studied in differential scanning calorimeter (DSC) (Dupont 910). Glass transition temperatures $\left(T_{g}\right)$ of cured epoxy and epoxy-PS blends were also determined from the same instrument. A heating rate of $10^{\circ} \mathrm{C} / \mathrm{min}$ was used and sample weight was about $20 \mathrm{mg}$. Dynamic mechanical analysis (DMA) was carried out in a Rheometric Dynamic Mechanical Thermal Analyser (MKT III) at a fixed frequency of $1 \mathrm{~Hz}$ with $3^{\circ} \mathrm{C} / \mathrm{min}$ heating rate using liquid nitrogen for subambient region. 


\subsection{Curing procedure}

Liquid polysulfone was dissolved into the epoxy resin without any solvent by stirring at room temperature. Required amount of hardener (HY 951) was subsequently added, mixed thoroughly and poured into Teflon mold. The curing cycle was $24 \mathrm{~h}$ at room temperature and $2 \mathrm{~h}$ at $150^{\circ} \mathrm{C}$.

\section{Results and discussions}

Poly (ethylene glycol adipate) and PS were characterized by ${ }^{13} \mathrm{C}$ NMR analysis (figure 1). Two peaks at 174.2 and $172.6 \mathrm{ppm}$ in the NMR spectra of adipate intermediate can be attributed to the existence of carboxylic and ester carbon. On subsequent formation of PS, intensity of the peak at $174.2 \mathrm{ppm}$ decreases substantially and an additional peak appears at $171.7 \mathrm{ppm}$. This indicates that further reaction has occurred leading to the formation of amide linkage. The appearance of amide carbon peak at lower ppm is expected as electronegativity of nitrogen is lower than that of oxygen and thereby --NH imparts lower deshielding effect to $-\mathrm{C}=\mathrm{O}$ carbon than -OH group.

In IR spectra a broad peak at carbonyl region $\left(1710-1740 \mathrm{~cm}^{-1}\right)$ is observed rather than separate peaks for carboxyl. ester and amide. This can be attributed to hydrogen bonding.

The physico-chemical properties of PFG adipate and PS are summarized in table 1. From the table it is evident that acid value decreases as a result of the formation of PS and viscosity increases drastically due to increase in the chain length. The close proximity of solubility parameters $(\dot{\delta}=0.4)$ indicates high level of compatibility of PS with epoxy since both are of low molecular weight.

DSC traces of epoxy and PS mixture without any hardener are shown in figure 2. The exothermic nature of the plot at $100^{\circ} \mathrm{C}$ indicates reaction of PS with epoxy at elevated temperature. DSC scan of epoxy-PS blend network cured for two days using hardener shows residual exotherm (figure 3). The same sample when further cured for $2 \mathrm{~h}$ at $150 \mathrm{C}$, shows no residual exotherm and glass transition region shifts to higher temperature which indicates further crosslinking at elevated temperature. All the blend networks exhibit single glass transition temperature $\left(T_{\mathrm{g}}\right)$ which gradually decreases with increase of PS concentration (table 2). This indicates that PS forms compatible blend with epoxy and it imparts flexibility to the epoxy matrix. Similar observation was reported in the literature (Monternal et al 1989) where high acrylonitrile content CTBN was used as modifier. The dynamic mechanical properties obtained for pure epoxy and epoxy/PS blend $(10(0 \cdot 30)$ are shown in figure 4 where loss factor $(\tan \delta)$ measured at $1 \mathrm{~Hz}$ is plotted against temperature. The exhibition of single relaxation peak indicates complete miscibility. DMA results of all epoxyPS blends (table 3 ) reveal that the dynamic modulus and $\tan \delta$ peak temperature gradually decrease with increase of PS concentration which supports the DSC results. However, all the blends exhibit higher $\tan \delta^{\max }$ indicating better dissipation of mechanical energy. The difference between the exact temperature for glass transition $\left(T_{g}\right)$ from DSC and from DMA is about $20^{\circ} \mathrm{C}$. It is expected due to the difference in the methods of measurement involved and different definitions of transition temperature used. 


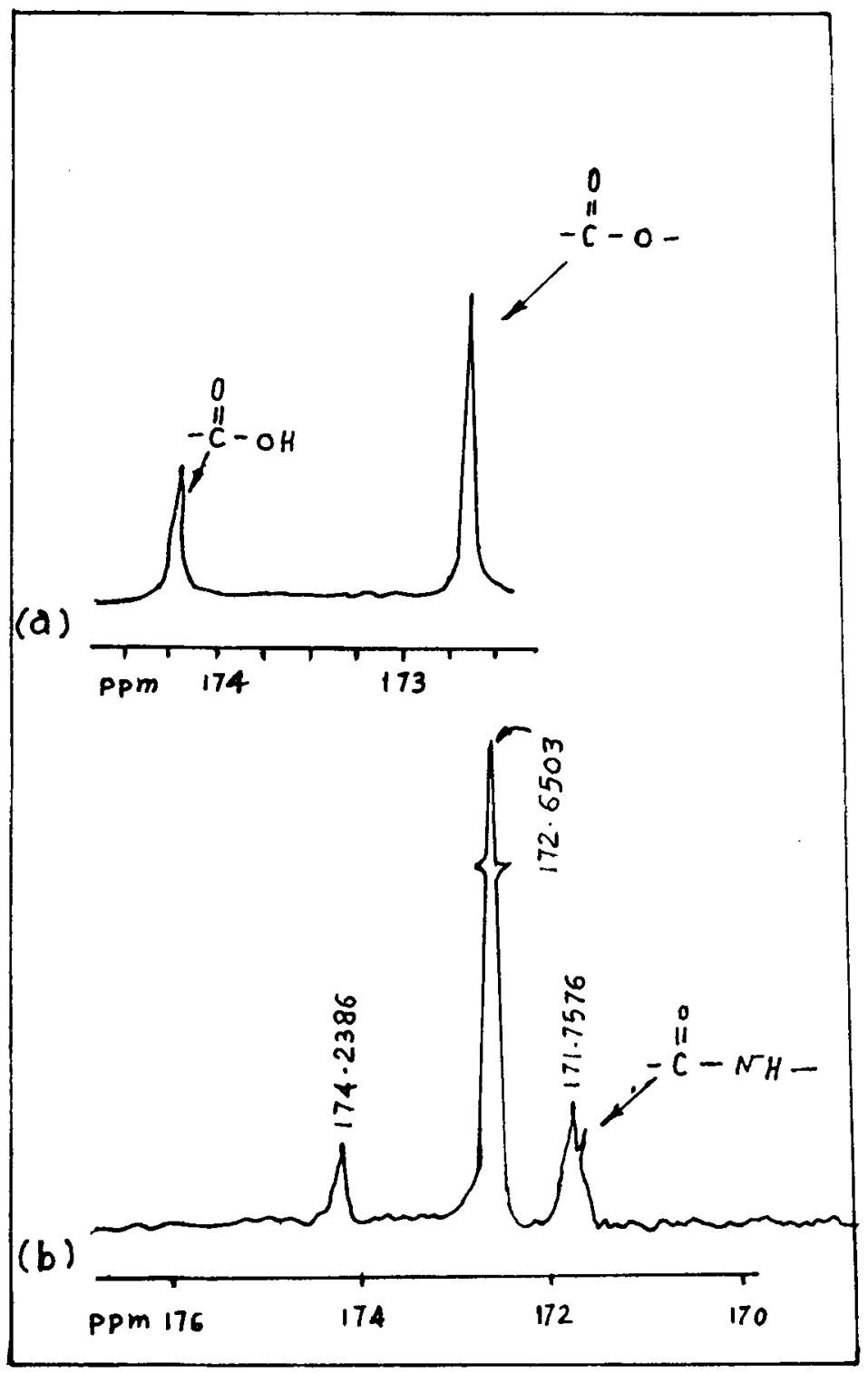

Figure 1. Carboxyl region of ${ }^{13} \mathrm{C}$ spectra of (a) CTPA and (b) PS.

Table 1. Physicochemical properties of PS.

\begin{tabular}{lccc}
\hline Resin & $\begin{array}{c}\text { Acid value } \\
\text { (mg. of KOH/g) }\end{array}$ & $\begin{array}{c}\text { Viscosity } \\
(\mathrm{Pa} . \mathrm{S})\end{array}$ & $\begin{array}{c}\text { Solubility parameter } \\
\text { (cal/cc) }\end{array}$ \\
\hline CTPA & 90 & $1 \cdot 3$ & $10 \cdot 81$ \\
PS & 20 & $67 \cdot 8$ & $10 \cdot 61$ \\
LY 556 & - & 7.4 & $10 \cdot 32$ \\
\hline
\end{tabular}

* at $26^{\circ} \mathrm{C}$ 


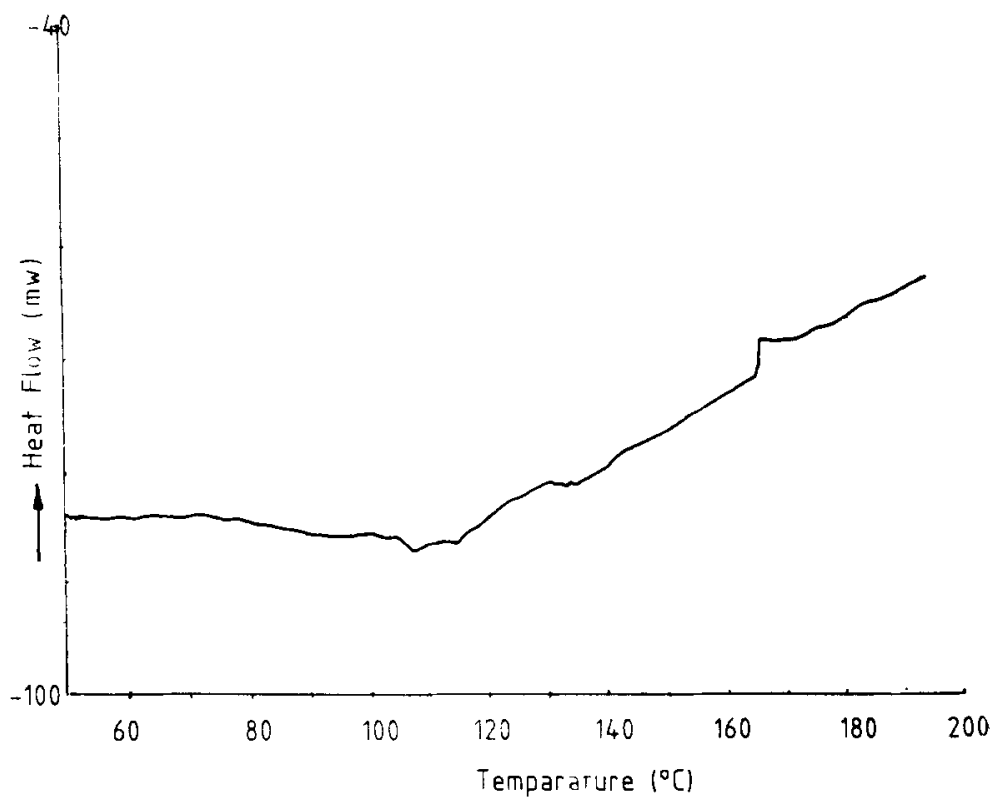

Figure 2. DSC scan of epoxy and PS mixture without hardener.

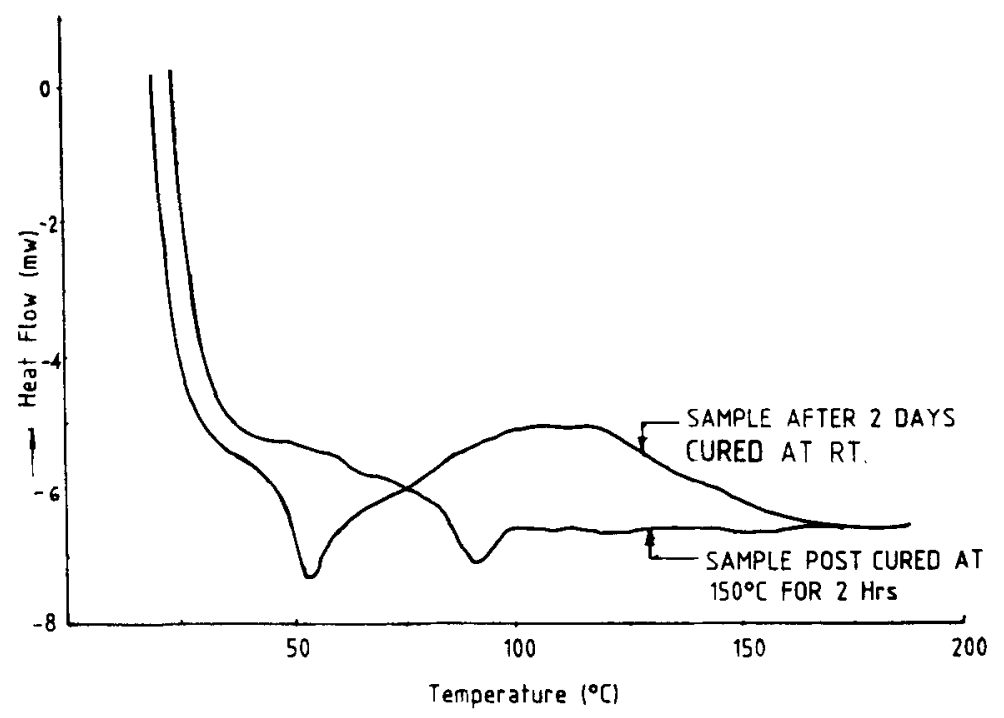

Figure 3. DSC spectra of cured blend (100:30) before and after post curing.

Table 2. DSC analysis of epoxy/PS blends.

\begin{tabular}{lc}
\hline $\begin{array}{l}\text { Composition of blends } \\
(\text { LY 556/PS) }\end{array}$ & $\begin{array}{c}\text { Glass transition } \\
\text { temperature }\left({ }^{\circ} \mathrm{C}\right)\end{array}$ \\
\hline $100 / 10$ & 115 \\
$100 / 10$ & 103 \\
$100 / 20$ & 95 \\
$100 / 30$ & 82 \\
\hline
\end{tabular}




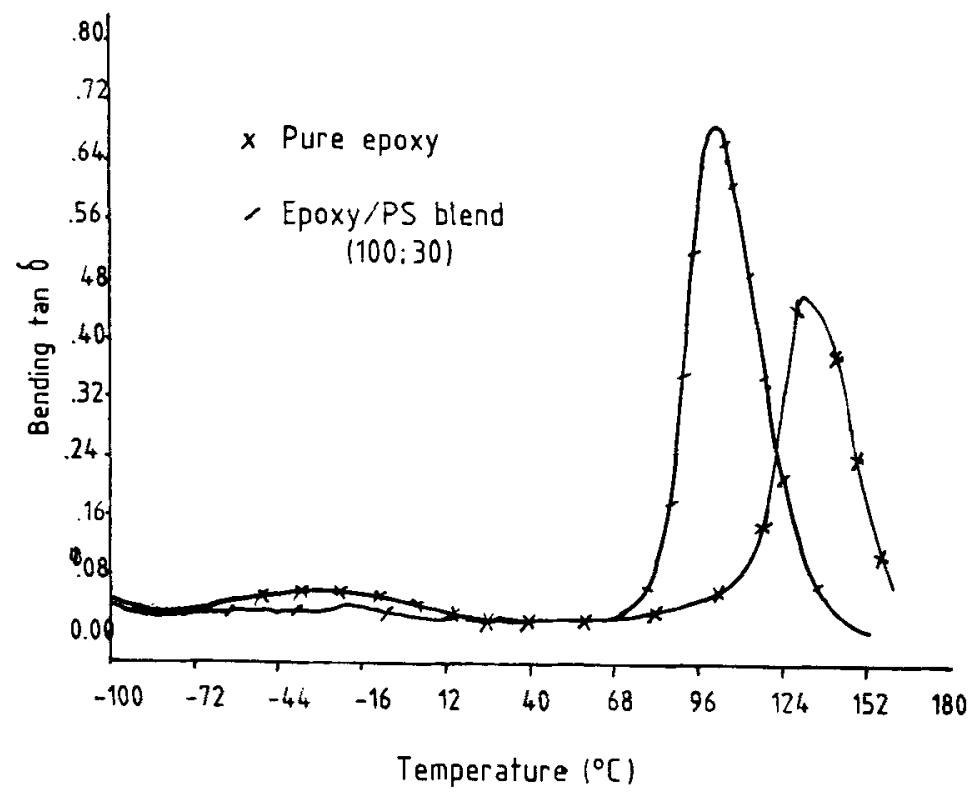

Figure 4. DMA analysis of epoxy and epoxy/PS blend network.

Table 3. DMA analysis of epoxy/PS blends.

\begin{tabular}{lccc}
\hline $\begin{array}{l}\text { Composition } \\
\text { of blends } \\
\text { (LY 556/PS) }\end{array}$ & $\begin{array}{c}\text { Storage } \\
\text { modulus } \# \\
\text { (GPa) }\end{array}$ & $\begin{array}{c}\tan \delta \text { peak } \\
\text { temperature } \\
\left({ }^{\circ} \mathrm{C}\right)\end{array}$ & $\begin{array}{c}\text { Max } \tan \delta \\
\text { value }\end{array}$ \\
\hline $100 / 0$ & 2.63 & 139 & 0.60 \\
$100 / 10$ & 2.08 & 126 & 0.71 \\
$100 / 20$ & 1.50 & 117 & $0 \cdot 66$ \\
$100 / 30$ & 1.27 & 106 & 0.74 \\
\hline
\end{tabular}

$\#$ at $35^{\circ} \mathrm{C}$

\section{Conclusion}

A low molecular weight polysulfone (PS) has been developed which forms compatible blends with epoxy resin. The developed PS can be used as a flexibiliser for cured epoxy matrix.

\section{Acknowledgements}

Authors are thankful to Smt. Lalita Chandrashekhar for her help in measurements in DSC and DMTA and Sri Uttam G. Suryawanshi for assisting in experimental work.

\section{References}

Banthia A K, Chaturvedi P N, Jha V and Pendyala V N S 1989 in Rubber toughened plastics; Advances in chemistry series 222 (eds) C K Reiw (Washington DC: American Chem. Soc.) p. 333 
Bascom W D and Hunston D L 1989 in Rubber toughened plastics, Advances in chemistry series 222 (eds) C K Reiw (Washington DC: American Chem. Soc.) p. 193

Bauer R S, Stenzenberger H D and Romer W 1989 34th Int. SAMPE Symp. 8 p. 312

Bucknall C B and Gilbert A H 1989 Polymer 30213

Hansen C M 1967 J. Paint Technol. 39 104, 511

Ijima T, Tochiomoto T and Tomoi M 1991 J. Appl. Polym. Sci. 431685

Jang B Z, Lian J Y, Hwang L R and Shih W K 1989 J. Reinf. Plast. 8312

McGarry F J and Willner A M 1968 in Toughening of an epoxy resin by an elastomer second phase. R68-8, MIT

Monternal S, Pascault J P and Santereau H 1989 in Rubber toughened plastics, Advances in chemistry series 222 (Washington DC: American Chem. Soc.) p. 193

Pak S J, Lyle G D, Mercier R and McGrath J E 1993 Polymer 34885

Peters R A and Logan T J 1975 Adhesive Age 17

Reiw C K 1981 Rubber Chem. Technol. 54374

Riffle J S, Yilgor I, Banthia A K, Wilkes G L and McGrath J E 1982 Org. Coat. Appl. Polym. Sci. Proc. 46397

Slysh R 1970 in Epoxy resins, Advances in chemistry series 154 (Washington DC: American Chem. Soc.) p. 108

Yee A F and Pearson R A 1990 Polym. Mater. Sci. Eng. 63311 